\title{
International Quit and Win 1996: comparative evaluation study in China and Finland
}

Su Sun, Tellervo Korhonen, Antti Uutela, Heikki J Korhonen`, Pekka Puska, Yan Jun, Yao Chonghua, Guo Zeyu, Wu Yonghao, Xu Wenqing

\begin{abstract}
Objectives-To compare background and process variables, as well as follow up status, of the participants in the International Quit and Win'96 contests of China and Finland, and analyse factors contributing to sustained maintenance.

Design-A standardised 12 month follow up was conducted in both countries with random samples of participants. The sample sizes were 3119 in China and 1448 in Finland, with response rates of $91.2 \%$ and $65.2 \%$, respectively.
\end{abstract}

Interventions-The International Quit and Win '96 contest was the second coordinated, multinational smoking cessation campaign targeted at adult daily smokers. Altogether 25 countries participated, including China with 15000 and Finland with 6000 smokers registered.

Main outcome measures-Conservative (considering all non-respondents relapsed) and non-conservative (based on respondents only) estimates were calculated for one month abstinence, 12 month continuous abstinence, and point abstinence at the time point of follow up.

Results-Great differences were found in the background and process variables, as well as in the outcome measures. At one year follow up, the conservative continuous abstinence rates show that the Chinese participants maintained their abstinence better (38\%) compared to the Finnish ones $(12 \%)$. In China women reached higher abstinence rate $(50 \%)$ than men (36\%), whereas in Finland men achieved a better result (14\%) than women (9\%).

Conclusions-The Quit and Win contest is a mass smoking cessation method feasible in countries showing great variance in smoking habits and rates. However, in countries with different stages of antismoking development, such as China and Finland, different practical implementation strategies may be needed.

(Tobacco Control 2000;9:303-309)

Keywords: smoking cessation; Quit and Win; China; Finland

The Quit and Win contest was developed in the USA in the $1980 \mathrm{~s}^{1-3}$ The idea was adapted and modified in Finland, first in North Karelia as part of the North Karelia Project and then nation wide. ${ }^{45}$ Thereafter, similar contests were implemented in a number of other countries..$^{6-9}$ The first International Quit and Win contest was arranged in 1994 using a network that was originally based on the World Health Organization's (WHO) Countrywide integrated non-communicable disease intervention (CINDI) programme in Europe. ${ }^{10}$ Thirteen countries joined the effort coordinated by the Finnish National Public Health Institute (KTL).

The one year maintained quit rates in the Quit and Win contests have varied between $15 \%$ and $30 \%$, not being dependent on the smoking prevalence rates and their present trends, but on sex, age, previous amount of smoking, and earlier quit attempts of the participants. ${ }^{11}{ }^{12}$ The Quit and Win contest has been shown to be a feasible and cost effective community based smoking cessation method. ${ }^{13}$

The second International Quit and Win was organised in 1996 with 25 countries participating. KTL from Finland coordinated the international implementation and evaluation of the campaign. China took part in this international effort for the first time, with a quite different social-cultural background and health care system compared to other participating countries. The campaigns were organised in five districts of Beijing and eight districts of Tianjin, as well as in some factories of Shanghai. These districts belong to the intervention areas of the "Health 7 Project". The total target population was about 500000 eligible smokers. Altogether over 15000 participants were registered. The 1996 Quit and Win was Finland's fourth national contest, conducted within the "Smoke-free Finland" program. The target population was 950000 , and over 6600 smokers registered.

The smoking patterns are different in China and in Finland. In 1996 the prevalence of daily smokers in China was $61 \%$ among men and $3 \%$ among women, ${ }^{14}$ whereas the corresponding rates in Finland were $27 \%$ and $18 \%$. Between 1986 and 1996 smoking prevalence among Chinese men had increased 5\% units, but decreased 5\% units among Finnish men. ${ }^{15}$ More than half of all smokers in Finland indicated willingness to quit, whereas only $17 \%$ did so in China. ${ }^{14} 15$

The Quit and Win contest as such is better established in Finland. We could assume that this may lead to higher participation rates compared to those in China. On the other hand, initiatives like Quit and Win may raise great public attention when arranged for the first time. The relatively high smoking rates among men in China may suggest that a larger 
percentage of smokers could be able to quit easily in comparison to the situation in Finland. As for the low percentage of China's female smokers, this may suggest that there are considerable social norms against female smoking which may favour the cessation rate in that country. ${ }^{14} 15$

China and Finland have different socialdemographic and cultural backgrounds, being in different stages of anti-smoking health policy development. Applying the experience of the International Quit and Win '96, this study aimed to: (1) compare the background and process factors among quitters in the two countries; (2) analyse whether the contest's abstinence rates reflected the social-cultural and demographic factors and the different anti-smoking intervention backgrounds; and (3) analyse the factors contributing to successful cessation maintenance at the two study sites.

\section{Methods}

IMPLEMENTATION STRATEGIES

China's campaign was organised by the Department of Disease Control of the Ministry of Health and coordinated by the National Health Education Institute. The health bureaus of Beijing and Tianjin coordinated the contest locally. In Beijing, the Municipal Office for Cardiovascular Disease Control provided technical guidance. Governmental institutions - that is, the Ministry of Health and local health bureau-played an important role in getting health sectors, organisations, and mass media involved. Thus, most of the important local mass media agencies in the two cities were involved in distributing information (through television and radio spots, and newspaper coverage) and motivating people to take part in the campaign. Twenty organisations for health education delivered 60000 invitations to residences. The entry forms were also distributed by registration stations, which were set up in the city's five districts during the period. All participants received a free pack of nicotine gum when registered in the contest. The total direct costs were US $\$ 18000$.

In Tianjin, 200000 pieces of Quit and Win information were distributed to residences, and advertisements were placed on buildings of the main street, in hospitals, and in schools. A workshop on methods to help cessation was arranged and reported by mass media. Health centre personnel were advised to motivate participants and distribute registration forms like in Beijing. Also here, all participants received a free pack of nicotine gum to assist cessation. The costs of the Tianjin campaign were $\$ 21690$.

In Finland, the Finnish Centre for Health Promotion (FCHE) coordinates a long term national program "Smoke-free Finland", which comprises a network of some 15 public health organisations. The 1996 Quit and Win was carried out within the framework of this program. To recruit participants, information on the Quit and Win was released at a press conference. Five press releases with background information, human interest stories, and campaign material were sent to the media before the contest. Newspapers and magazines published over 200 articles about the contest and over 40 radio interviews were given. Registration forms were published in magazines and newspapers and distributed by health and educational institutions, pharmacies, and members of Smoke-free Finland organisations. The national expenditure for the Finnish campaign was $\$ 110000$.

\section{SUBJECTS}

A standardised one year follow up survey was conducted in 1997 in China and Finland. The city of Shanghai was excluded from the evaluation since the contest was arranged in selected factories only. There were 5962 participants in Beijing and 7886 in Tianjin. The original random sample of the follow up survey in China numbered 3277 (1777 in Beijing and 1500 in Tianjin). In Finland a random sample size of 1500 of the 6038 national participants was used. In the province of North Karelia in Finland, all 601 participants were followed, but since an intensified campaign was arranged it was considered a special population and excluded from this study. One hundred and sixty Chinese and two Finnish participants were excluded from the samples because they had died or emigrated, or were under the age of 18 years. Finally, the purified samples included 3119 subjects in China and 1448 in Finland.

Telephone interviews only were used in Beijing, whereas Tianjin used both face-to-face and telephone interviews. Data for Finland's contest were collected through mailed questionnaires. Three reminders were sent to the non-respondents. The response rates were $91.2 \%$ in China and $65.2 \%$ in Finland. The final data included 2841 respondents in China (1645 in Beijing and 1196 in Tianjin) and 944 in Finland.

\section{VARIABLES}

The distribution of background variables were compared among the sample and the respondents of the follow up. The data came from two sources: the participant entry forms and the follow up survey carried out at 12 months. Background variables, such as sex, age, tobacco consumption and years of smoking were drawn from the entry forms, while marital status and education variables were obtained from the follow up respondents only.

As possible determinants of successful cessation, the process variables included intention to quit, special measures used (nicotine replacement therapy and/or non-pharmacological measures), support received (from family, friends/co-workers, health personnel), information received (from media channels, family, health personnel), previous cessation attempts, reasons for relapse (lack of support or information, stress, weight or alcohol problems, withdrawal symptoms, environment), and the contest itself. The background variables were age, sex, marital status and educational level, daily tobacco consumption, and years of smoking. 
Cessation periods of one month and 12 months were used as outcome variables. One month abstinence was assessed with the question "Did you succeed in completely abstaining from smoking during the month of the Quit \& Win?". One year abstinence was assessed with the question "What has been your smoking situation during the year after the start of the Quit \& Win?". The options were: (1) "I have not smoked at all"; (2) "I have smoked, but not regularly and presently I do not smoke at all"; (3) "I have smoked regularly but presently I do not smoke at all"; and (4) "I have smoked and smoke presently".

Three kinds of smoking cessation rates were calculated. The first was the one month abstinence, including those who reported total abstinence for the contest period. The second was the "continuous" abstinence rate, including only those who reported to be smoke free for the whole follow up period of 12 months. The third was the "point abstinence" rate, including all quitters reporting being nonsmokers at the time point of the follow up survey. Two estimates were calculated for the abstinence rates: first, the so-called "nonconservative" estimate as a proportion of abstainers among the respondents; and second, the so-called "conservative" estimate as a proportion of abstainers among the follow up sample where non-respondents were considered smokers.

\section{STATISTICAL ANALYSES}

The background variables were categorised following the standardised evaluation procedures of the international campaign completed in altogether 22 sites. $^{16}$ All analyses were conducted separately for each country and sex. In order to analyse the determinants of cessation, a logistic regression model, including background and process variables, was used. The results are presented as odds ratios (OR), with $95 \%$ confidence intervals (CI).

\section{Results}

China's regional contests included a total of 13848 participants, which was $1.0 \%$ of eligible smokers, while the national contest in Finland recruited 6038 participants, being $0.7 \%$ of the targeted population.

BACKGROUND VARIABLES

The findings presented in table 1 suggest that respondents to the follow up surveys represent the total samples originally drawn within each country. Concerning the differences between the two countries and two sexes, the Chinese participants were more often men, older, and lighter smokers with fewer previous quit attempts. Marital status differed greatly as well. More than $90 \%$ of the Chinese participants were married or cohabiting, compared with $55-70 \%$ of the Finnish participants. On average, the Finnish participants had completed more years of education.

\section{PROCESS VARIABLES}

The distribution of six process variables are presented in table 2. About $75 \%$ of participants in both countries intended to quit smoking permanently with the contest. A higher proportion of Chinese participants reported use of nicotine replacement in comparison to their Finnish counterparts, who used other aids more often. Some $80 \%$ of the respondents from China reported that they had received family support, compared to $50 \%$ in Finland. Support from friends/co-workers, health personnel or other sources was also more frequent among the Chinese quitters.

Most of the Chinese participants indicated that they had learned of the contest through radio, television, newspapers, magazines, family members, friends/co-workers or health personnel, whereas only half of their Finnish counterparts said so. Social smoking was the most important reason for relapse among the Chinese participants, while a stressful situation was the reason cited most often by the relapsed Finnish participants. In China, further reasons

Table 1 Background information on participants in the purified sample and among the respondents (\%)

\begin{tabular}{|c|c|c|c|c|c|c|c|c|}
\hline \multirow[b]{3}{*}{ Variable } & \multicolumn{4}{|l|}{ China } & \multicolumn{4}{|l|}{ Finland } \\
\hline & \multicolumn{2}{|l|}{ Sample } & \multicolumn{2}{|c|}{ Respondents } & \multicolumn{2}{|l|}{ Sample } & \multicolumn{2}{|c|}{ Respondents } \\
\hline & $\begin{array}{l}\text { Men } \\
(n=2789)\end{array}$ & $\begin{array}{l}\text { Women } \\
(n=330)\end{array}$ & $\begin{array}{l}\text { Men } \\
(n=2556)\end{array}$ & $\begin{array}{l}\text { Women } \\
(n=285)\end{array}$ & $\begin{array}{l}\text { Men } \\
(n=818)\end{array}$ & $\begin{array}{l}\text { Women } \\
(n=630)\end{array}$ & $\begin{array}{l}\text { Men } \\
(n=506)\end{array}$ & $\begin{array}{l}\text { Women } \\
(n=438)\end{array}$ \\
\hline \multicolumn{9}{|l|}{ Age (years) } \\
\hline $18-29$ & 14.8 & 5.8 & 14.5 & 6.0 & 34.1 & 38.4 & 28.5 & 36.5 \\
\hline $30-39$ & 26.8 & 15.2 & 26.8 & 14.7 & 29.2 & 29.1 & 29.6 & 36.5 \\
\hline $40-49$ & 34.1 & 27.3 & 34.7 & 28.8 & 24.5 & 21.4 & 26.3 & 21.2 \\
\hline $50+$ & 24.4 & 51.9 & 24.0 & 50.3 & 12.2 & 11.1 & 15.6 & 12.8 \\
\hline \multicolumn{9}{|c|}{ Tobacco consumption/day } \\
\hline $1-14$ & 44.0 & 73.0 & 44.1 & 72.6 & 26.6 & 42.2 & 26.7 & 41.6 \\
\hline $15+$ & 56.0 & 27.0 & 55.9 & 27.3 & 73.4 & 57.8 & 73.3 & 58.4 \\
\hline \multicolumn{9}{|c|}{ Previous quit attempts } \\
\hline None & 58.3 & 66.6 & 58.6 & 66.6 & 10.2 & 6.2 & 8.5 & 5.5 \\
\hline $1-2$ & 31.2 & 23.1 & 30.9 & 22.5 & 36.7 & 35.7 & 37.0 & 35.3 \\
\hline $3+$ & 10.4 & 10.3 & 10.5 & 10.9 & 53.1 & 58.1 & 54.5 & 59.4 \\
\hline \multicolumn{9}{|l|}{ Years of smoking } \\
\hline $1-9$ & 19.4 & 39.2 & 19.2 & 39.1 & 29.1 & 33.8 & 24.2 & 32.4 \\
\hline $10-19$ & 29.4 & 19.8 & 29.6 & 19.0 & 33.2 & 33.8 & 33.1 & 32.4 \\
\hline $20+$ & 51.2 & 41.3 & 51.2 & 41.9 & 37.7 & 32.4 & 42.7 & 34.2 \\
\hline \multicolumn{9}{|l|}{ Marital status } \\
\hline Living together & - & - & 90.4 & 91.6 & - & - & 69.9 & 54.9 \\
\hline Living alone & - & - & 9.6 & 8.4 & - & - & 30.1 & 45.1 \\
\hline \multicolumn{9}{|l|}{ Years of education } \\
\hline $0-12$ & - & - & 62.1 & 81.4 & - & - & 49.8 & 41.1 \\
\hline $13+$ & - & - & 37.9 & 18.6 & - & - & 50.2 & 58.9 \\
\hline
\end{tabular}


Table 2 Distributions of the process variables among the respondents (\%)

\begin{tabular}{|c|c|c|c|c|}
\hline \multirow[b]{2}{*}{ Variable } & \multicolumn{2}{|l|}{ China } & \multicolumn{2}{|l|}{ Finland } \\
\hline & $\begin{array}{l}\text { Men } \\
(n=2556)\end{array}$ & $\begin{array}{l}\text { Women } \\
(n=285)\end{array}$ & $\begin{array}{l}M e n \\
(n=506)\end{array}$ & $\begin{array}{l}\text { Women } \\
(n=438)\end{array}$ \\
\hline \multicolumn{5}{|l|}{ Intention } \\
\hline Stop completely & 76.3 & 82.5 & 75.1 & 74.7 \\
\hline Quite for 1 month & 4.0 & 3.5 & 15.1 & 15.6 \\
\hline Reduce smoking & 19.7 & 14.0 & 9.8 & 9.6 \\
\hline \multicolumn{5}{|l|}{ Special measures used ${ }^{\star}$} \\
\hline No measures & 36.2 & 45.3 & 55.7 & 60.8 \\
\hline Nicotine chewing gum & 28.0 & 29.2 & 21.3 & 19.3 \\
\hline Nicotine patch & 17.6 & 12.3 & 19.1 & 17.2 \\
\hline Others & 4.6 & 5.3 & 14.7 & 13.0 \\
\hline \multicolumn{5}{|l|}{ Support received ${ }^{\star}$} \\
\hline No support & 13.0 & 26.0 & 29.7 & 28.9 \\
\hline Family members & 80.2 & 81.8 & 54.7 & 49.2 \\
\hline Friends/co-workers & 54.4 & 55.8 & 32.1 & 48.7 \\
\hline Health personnel & 41.7 & 46.0 & 7.1 & 6.7 \\
\hline Someone else & 15.7 & 21.1 & 3.6 & 2.1 \\
\hline \multicolumn{5}{|l|}{ Information received ${ }^{\star}$} \\
\hline Radio/TV & 27.8 & 33.3 & 12.5 & 15.4 \\
\hline Newspaper/magazine & 47.7 & 43.5 & 29.8 & 33.3 \\
\hline Family member & 25.7 & 33.0 & 15.5 & 7.1 \\
\hline Friend/co-worker & 32.6 & 35.6 & 16.5 & 16.8 \\
\hline Health personnel & 43.7 & 44.6 & 11.5 & 10.6 \\
\hline Somewhere else & 5.6 & 6.0 & 38.6 & 44.4 \\
\hline Don't remember & 3.0 & 3.5 & 6.2 & 5.8 \\
\hline \multicolumn{5}{|l|}{ Reason for relapse } \\
\hline Lack of support & 4.0 & 5.1 & 5.6 & 4.7 \\
\hline Lack of information & 4.1 & 2.8 & 0.0 & 0.0 \\
\hline Stressful situation & 13.7 & 8.6 & 28.0 & 34.9 \\
\hline Weight increase & 0.5 & 1.4 & 1.2 & 4.1 \\
\hline Alcohol related situation & 1.9 & 0.5 & 14.9 & 14.2 \\
\hline Withdrawal symptoms & 10.0 & 9.2 & 23.0 & 17.1 \\
\hline Smoking in environment & 18.3 & 11.9 & 16.8 & 17.6 \\
\hline Other & 12.2 & 11.0 & 10.6 & 7.1 \\
\hline \multicolumn{5}{|l|}{ Help of the contest } \\
\hline Important & 66.5 & 76.8 & 35.8 & 42.5 \\
\hline A little & 25.4 & 16.5 & 42.9 & 40.7 \\
\hline Not at all & 7.3 & 6.0 & 9.3 & 7.6 \\
\hline Don't know & 0.8 & 0.8 & 12.1 & 9.2 \\
\hline
\end{tabular}

${ }^{\star}$ Multiple choice possible.
Chinese men, whereas Finnish men had better results than Finnish women.

DETERMINANTS FOR SUCCESSFUL QUITTING

Table 4 shows the ORs separately for men and women in China and Finland. The 95\% CIs show that, in terms of the background variables, older participants tended to be more successful, but significantly only in Finland. Lighter smokers managed better, except among Finnish men. Cohabitation tended to be a successful determinant for cessation among men, but significant among Finnish men only. Lower education was negatively associated with maintained cessation among Chinese women only.

Concerning the process variables, the number of previous cessation attempts was not a significant determinant, although those with more previous attempts tended to be less successful. Family support was positively related to abstinence among Finnish women only. Support from health professionals had a negative result among Chinese men, whereas support from friends or co-workers helped them significantly. Finnish women succeeded better if they received support from health professionals. The role of special measures, such as nicotine replacement therapy, was not a significant determinant, although a positive trend was suggested by the ORs.

\section{Discussion}

In general, sizeable differences existed in the background and process variables as well as in the factors contributing to successful cessation maintenance in the two countries. In the short run, the Finnish participants were more successful in cessation. In the long run, however, the Chinese participants succeeded better.

or them to quit, a hir proportion of participants in China than in Finland agreed.

ABSTINENCE RATES

In the short run-that is, one month follow up-the Finnish participants managed better than their Chinese counterparts (table 3). In China, women were more successful than men, and in Finland the abstinence rates were roughly the same between the sexes. In the long run - that is, one year follow up-the Chinese participants faired better. Chinese women reached higher rates of abstinence than

VALIDITY OF RESULTS

Concerning the background variables of the subjects, we did not detect any non-respondent bias in this study. Presumably, however, unsuccessful quitters may be less likely to respond to surveys focused on quitting. To control this bias, the success rates were also calculated as a proportion of the whole sample-the so-called conservative estimate. This particularly makes sense for Finland, where the response rate was quite low. We may assume that the actual suc-

Table 3 Abstinence rates in one month and 12 month follow up among the respondents and in the samples (\%)

\begin{tabular}{|c|c|c|c|c|c|c|}
\hline & \multicolumn{3}{|l|}{ China } & \multicolumn{3}{|l|}{ Finland } \\
\hline & Men & Women & Total & Men & Women & Total \\
\hline Respondents & $n=2556$ & $\mathrm{n}=285$ & $\mathrm{n}=2841$ & $\mathrm{n}=506$ & $\mathrm{n}=438$ & $\mathrm{n}=944$ \\
\hline 1 month abstinence rate & 48.2 & 67.0 & 50.1 & 69.6 & 61.6 & 65.9 \\
\hline 12 month continuous abstinence rate ${ }^{\star}$ & 39.9 & 58.3 & 41.7 & 22.5 & 13.2 & 18.2 \\
\hline 12 month point abstinence rate $\dagger$ & 54.1 & 68.1 & 55.5 & 40.1 & 34.9 & 37.7 \\
\hline Sample $\ddagger$ & $\mathrm{n}=2789$ & $\mathrm{n}=330$ & $n=3119$ & $\mathrm{n}=818$ & $\mathrm{n}=630$ & $\mathrm{n}=1448$ \\
\hline 1 month abstinence rate & 44.3 & 57.9 & 45.7 & 43.0 & 42.9 & 43.0 \\
\hline 12 month continuous abstinence rate & 36.5 & 50.3 & 38.0 & 13.9 & 9.2 & 11.9 \\
\hline 12 month point abstinence rate & 49.6 & 58.8 & 50.6 & 24.8 & 24.3 & 24.9 \\
\hline
\end{tabular}

* Those who were smoke free for the whole follow up of 12 months.

tAll quitters reporting to be non-smokers at the time point of the follow up.

$\ddagger$ Considering all the non-respondents as smokers. 
Table 4 Determinants of 12 month abstinence after the quit date among the respondents: odds ratios (OR) and 95\% confidence intervals (CI) based on logistic regression

\begin{tabular}{|c|c|c|c|c|}
\hline \multirow[b]{2}{*}{ Variable } & \multicolumn{2}{|l|}{ China } & \multicolumn{2}{|l|}{ Finland } \\
\hline & $\begin{array}{l}\text { Men }(n=2556) \\
\text { OR }(95 \% C I)\end{array}$ & $\begin{array}{l}\text { Women }(n=285) \\
\text { OR }(95 \% C I)\end{array}$ & $\begin{array}{l}\text { Men }(n=506) \\
\text { OR }(95 \% C I)\end{array}$ & $\begin{array}{l}\text { Women }(n=438) \\
\text { OR }(95 \% \text { CI })\end{array}$ \\
\hline \multicolumn{5}{|l|}{ Age (years) } \\
\hline 40 or more & $1.23(0.96$ to 1.33$)$ & $0.62(0.37$ to 1.10$)$ & $1.61(1.02$ to 2.55$)$ & $3.01(1.60$ to 5.66$)$ \\
\hline 39 or less & 1.00 & 1.00 & 1.00 & 1.00 \\
\hline \multicolumn{5}{|l|}{ Tobacco consumption } \\
\hline $1-14$ & $1.45(1.23$ to 1.70$)$ & $2.36(1.37$ to 4.10$)$ & $0.70(0.42$ to 1.78$)$ & $2.13(1.18$ to 3.84$)$ \\
\hline $15+$ & 1.00 & 1.00 & 1.00 & 1.00 \\
\hline \multicolumn{5}{|l|}{ Marital status } \\
\hline Living together & $1.18(0.90$ to 1.53$)$ & $0.57(0.22$ to 1.48$)$ & $1.69(1.03$ to 2.77$)$ & $0.81(0.44$ to 1.49$)$ \\
\hline Living alone & 1.00 & 1.00 & 1.00 & 1.00 \\
\hline \multicolumn{5}{|l|}{ Education } \\
\hline $0-12$ grade & $0.92(0.78$ to 1.09$)$ & $0.50(0.25$ to 0.98$)$ & $0.85(0.55$ to 1.31$)$ & $1.46(0.81$ to 2.63$)$ \\
\hline $13+$ & 1.00 & 1.00 & 1.00 & 1.00 \\
\hline \multicolumn{5}{|l|}{ Previous quit attempts } \\
\hline Three or more & $1.18(0.91$ to 1.53$)$ & $0.71(0.32$ to 1.57$)$ & $0.85(0.56$ to 1.31$)$ & $0.56(0.31$ to 1.00$)$ \\
\hline Two or less & 1.00 & 1.00 & 1.00 & 1.00 \\
\hline \multicolumn{5}{|l|}{ Sources of support } \\
\hline Family & $1.16(0.94$ to 1.48$)$ & $1.28(0.70$ to 2.32$)$ & $0.95(0.59$ to 1.51$)$ & $2.07(1.14$ to 3.76$)$ \\
\hline No family & 1.00 & 1.00 & 1.00 & 1.00 \\
\hline Health professional & $0.53(0.44$ to 0.64$)$ & 1.17 (0.66 to 2.07$)$ & $1.35(0.60$ to 3.04$)$ & 2.89 (1.18 to 7.05$)$ \\
\hline No health professional & 1.00 & 1.00 & 1.00 & 1.00 \\
\hline Friend/co-worker/others & $1.90(1.58$ to 2.29$)$ & $1.54(0.94$ to 2.53$)$ & $1.00(0.64$ to 1.57$)$ & $0.95(0.52$ to 1.75$)$ \\
\hline No friend/co-worker/others & 1.00 & 1.00 & 1.00 & 1.00 \\
\hline \multicolumn{5}{|l|}{ Special measures used } \\
\hline Nicotine replacement/other measures & $1.17(0.99$ to 1.38$)$ & $1.46(0.85$ to 2.49$)$ & $0.96(0.62$ to 1.48$)$ & $1.16(0.63$ to 2.14$)$ \\
\hline No special measures & 1.00 & 1.00 & 1.00 & 1.00 \\
\hline
\end{tabular}

cess rates are between the conservative estimates and those based on the respondents only.

We did not use any biochemical measures to validate self reported smoking status. The Chinese used telephone and face-to-face interviews conducted by health personnel as data collection methods. To control possible bias from reactive effects, the interviewers provided instructions to motivate the interviewees to report truthfully. In Finland the data were collected by using an anonymous mailed questionnaire, which is likely less biased than data obtained with interview methods.

Although the continuous abstinence rates were low in Finland, the point abstinence rates were surprisingly high. In May 1997 the Smoke-free Finland programme launched a national Quit and Win contest again, which may contribute to the relatively high self reported point abstinence rates at the time point of the follow up.

In China, all participants received a free pack of nicotine gum, which may have caused high reporting on the use of nicotine replacement therapy. However, the pharmacological contents of these products may be different in Finland and China. Thus, the validity of the nicotine replacement's effectiveness was difficult to control in this study.

EFFECTIVENESS

The contest motivated 15000 registrations in the three target cities of China and 6000 in Finland. The high one month quitting rates (China 50.1\%, Finland $65.9 \%$ ) and one year point rates (China $55.5 \%$, Finland $37.7 \%$ ) may be an indication of the incentive effectiveness throughout the campaign. For China the campaign may have also built awareness of smoking cessation, and it may help to develop the country's future anti-smoking strategies. In addition to the measurable effects, this kind of community based campaign may have had positive effects on the cessation intentions of those who did not register in this contest. ${ }^{16}$

The background variables of the participants were different. Compared to Finland, the Chinese campaign attracted older participants, lighter smokers, and persons with fewer previous cessation attempts. On average, the Finnish participants had more years of education and a lower percentage of them were married. Among Chinese men, the proportion of contest participants aged $40-49$ years was 35\% whereas only $22 \%$ of daily smokers in the population was in this age group. In the age group 30-39 years, the corresponding rates were inverted: $26.8 \%$ and $32.7 \% .{ }^{14}$ It seems that recruitment was more successful among the age group $40-49$ years. This may indicate a need for future interventions in China to target younger age groups.

There were differences in implementation of the campaign in China and Finland. The Chinese campaign had a strong support from the governmental institutions and public health services whereas the Finnish one was mainly working through the coalition of the organisations joined in the "Smoke-free Finland" project, and through direct mailing to households. In addition to the international super prize of US $\$ 5000$, both campaigns attracted registrants by national or regional super prizes. The Chinese contest in Beijing had a main prize of about US $\$ 600$ in cash, whereas the Finnish national prize was a 10 day trip for one to the Atlanta Olympic Games where a young Finnish swimmer - a role model for many youngsters - was one of the winning candidates. ${ }^{16}$ These differences used for mobilisation may have contributed to the differences of the target groups actually reached.

Although the Finnish participants were more successful in one month abstinence $(65.9 \%)$ than their Chinese counterparts $(50.1 \%)$, the one year abstinence rate for 
China $(41.7 \%)$ was higher than for Finland $(18.2 \%)$. This result may be partly explained by the fact that China had a higher prevalence of less addictive quitters, as shown in table 1 . In Finland many of such "easy quitters" had already stopped as a result of previous anti-smoking campaigns. Thus, the Finnish participants included a higher proportion of smokers who may have more difficulties in cessation. ${ }^{17}$ The high cessation rates of Chinese women may be attributed to social influence and a higher proportion of lighter smokers. Finnish women handled short term cessation quite well, but relapsed more often than men in the long run, which echoes the results of earlier studies as well. ${ }^{1}$

Although we did not complete a formal cost effectiveness analysis, one could speculate by comparing the cost/participant and cost/ successful cessation estimates in two countries. The costs of the Chinese campaigns were altogether \$39690, whereas in Finland the national campaign costs were $\$ 110000$. As China had 13848 participants the cost per participant would be about $\$ 3$, whereas in Finland with 6038 participants the corresponding rate would be $\$ 18$. Still greater differences in cost effectiveness could be seen when comparing the cost per successful cessation estimates. When using the most conservative estimates of permanent cessation-38\% in China and 12\% in Finland-the Chinese campaign reached one target with $\$ 8$ only, whereas in Finland the cost of the target was $\$ 150$. This comparison shows a great difference in the cost effectiveness of the two campaigns. However, such a comparison may be too simple, and unfair, because the purchasing power of the US dollar in China and Finland is not comparable.

DETERMINANTS FOR SUCCESSFUL QUITTING

Older age groups of Finnish men were more successful than younger groups, which was a determinant for successful quitting in some previous studies. ${ }^{8}{ }^{10}{ }^{12}$ However, older Chinese women tended to be less successful than younger women. Three reasons might contribute to this result: (1) Chinese society accepts smoking among older women but not among younger women; (2) there was a high proportion of older female participants in the sample; and (3) older participants smoked more. ${ }^{14}$

In contrast to previous Quit and Win campaign reports, ${ }^{1918}$ this study found that a lesser amount of previous smoking was related to maintenance of quitting. This result, which is more logical than the ones of previous Quit and Win results, was true for all other groups, except the Finnish men. Like previous Quit and Win results, married or cohabiting male quitters in Finland were more successful. A similar result was not found among Finnish women or among the Chinese participants, although a Chinese survey indicated that those who live alone have a low cessation rate. ${ }^{14} \mathrm{Edu}-$ cation was a significant determinant for Chinese women only. Less educated Chinese women were less successful with cessation, which is supported by a previous Chinese study. ${ }^{14}$

There seems to be a big difference between the characteristics in the two countries, and perhaps also between the cultural norms relevant to smoking. In China adult male smoking is considered normal and socially accepted, but undesirable among females, especially young women. The average age of smoking onset among women is five years later than for men, and most female smokers are lighter smokers. ${ }^{14}$ China has only recently started to pass legislation to control smoking in some cities. In Finland, where smoking prevalence is quite similar among males and females, anti-smoking legislation and related health promotion methods have been in use since the 1970s. ${ }^{19}$

Previous studies in Finland, ${ }^{1}$ the $\mathrm{UK},{ }^{8}$ and Sweden $^{12}$ found that those who had made two or fewer previous attempts at quitting were more successful compared to those who had made three or more attempts. This difference was not found significant in this study, although the trend was the same in most cases. The reason why the number of cessation attempts was not a determinant may be, for the Chinese population, due to the fact that the Chinese smoking culture does not yet recognise quitting, since only about $10 \%$ of the participants had more than three attempts.

Family support was found to be an important factor related to success only among Finnish women. On the other hand, more than $80 \%$ of the Chinese participants reported that they received family support, a result which did permit much variation in this possible determinant. For the quitters who received health professional support, again we have a different picture, Chinese men being less successful and Finnish women more successful. A previous Quit and Win study in Finland ${ }^{10}$ showed that a combined support received from both health professionals and lay persons was a significant determinant. If the Chinese men did not succeed with help of health professionals, they did so with support of their friends and co-workers. This may be explained by Chinese culture, which in relation to the Finnish one may be considered to be more collective.

\section{CONCLUSIONS}

The Quit and Win campaign is a mass smoking cessation method that can be successfully implemented in different countries with variances in smoking habits and rates. However, China and Finland, which are at different stages in anti-smoking policy development, need different practical implementation strategies in future Quit and Win campaigns. China may learn from the Finnish experience of how to attract young smokers to participate, whereas Finland could test the Chinese experience of how to support the maintenance of cessation.

1 Glasgow RE, Klesges RC, Mizes JS, et al. Quitting smoking: strategies used and variables associated with success in a stop-smoking contest. F Consult Clin Psychol 1985;53:905- 
2 Elder JP, McGraw S, Rodrigues A, et al. Evaluation of two community-wide smoking cessation contests. Prev Med community-wide

3 Altman DG, Flora JA, Fortmann SP, et al. The costeffectiveness of three smoking cessation programs. Am $\mathcal{F}$ Public Health 1987;

4 Korhonen HJ, Niemensivu H, Piha T, et al. National TV smoking cessation program and contest in Finland. Prev Med 1992;21:74-87.

5 Puska P, McAlister A, Niemensivu $\mathrm{H}$, et al. A television format for national health promotion, Finland's "Keys to Health". Public Health Rep 1987;102:263-6.

6 Korhonen HJ, Puska P, Lipand A, et al. Combining mass media and contest in smoking cessation. Hygie 1993; 12:15-18.

7 Roberts C, Smith C, Catford J. Quit and Win Wales: an evaluation of the 1990 pilot contest. Tobacco Control 1993; evaluation

8 Chapman S, Smith W, Mowbray G, et al. Quit and Win smoking cessation contests: how should effectiveness be evaluated? Prev Med 1993;22:413-32.

9 Tillgren P. "Quit and Win" contests in tobacco cessation: theoretical framework and practices from a communitybased intervention in the Stockholm Cancer Prev Program. Academic dissertation. Sundbyberg: Karolinska Institutet, 1995

10 Korhonen T, Sun S, Korhonen HJ, et al. Evaluation of a national quit and win contest: determinants for successful quitting. Prev Med 1997;26:556-64.

11 King AC, Flora JA, Fortmann SP, et al. Smokers' challenge: immediate and long-term findings of a community smoking cessation contest. Am f Public Health 1987;77:1340-1.
12 Tillgren P, Haglund JA, Ainetdin T, et al. Who is a successful quitter? One-year follow-up of a national tobacco Ouit ful quitter? One-year follow-up of a national tobacco Quit 23:193-201.

13 Tillgren P, Rosen M, Haglund BJA, et al. Cost-effectiveness of a tobacco 'Quit and Win' contest in Sweden. Health Policy 1993;26:43-53.

14 Chinese Academy of Preventive Medicine, Department of Disease Control Ministry of Health, Chinese Association of Smoking or Health, Office of Committee of the National Patriotic Health Campaign. National Prevalence Survey of Smoking Pattern, 1996.

15 Helakorpi S, Uutela A, Puska P, et al. Health behaviour among Finnish adult population, spring 1996. Helsinki: Institute, 1996.

16 Korhonen T, Laaksonen M, Korhonen HJ, et al. International Quit and Win, 1996. Helsinki: National Public Health Institute, 1999

17 Korhonen T. Population-based smoking cessation: process evaluation of selected strategies used in the CINDI program. Academic Dissertation. Helsinki: National Public Health Institute, 1999.

18 Viinamäki H, Koskela K, Korhonen HJ, et al. A televised health programme, mini-intervention and cessation of health programme, mini-intervention and cessation of smoking. In: Shemeikka S, Nissinen A, eds. The yearbook of the health education research 1992 (in Fisnish with English summary). Helsinki: Ministry of Social Affairs and Health, 1993;1:151-9.

19 Puska P, Korhonen HJ, Uutela A, et al. Anti-smoking policy in Finland. In: Smokefree Europe: a forum for networks. Jyväskylä: Gummerus, 1997:26-42.

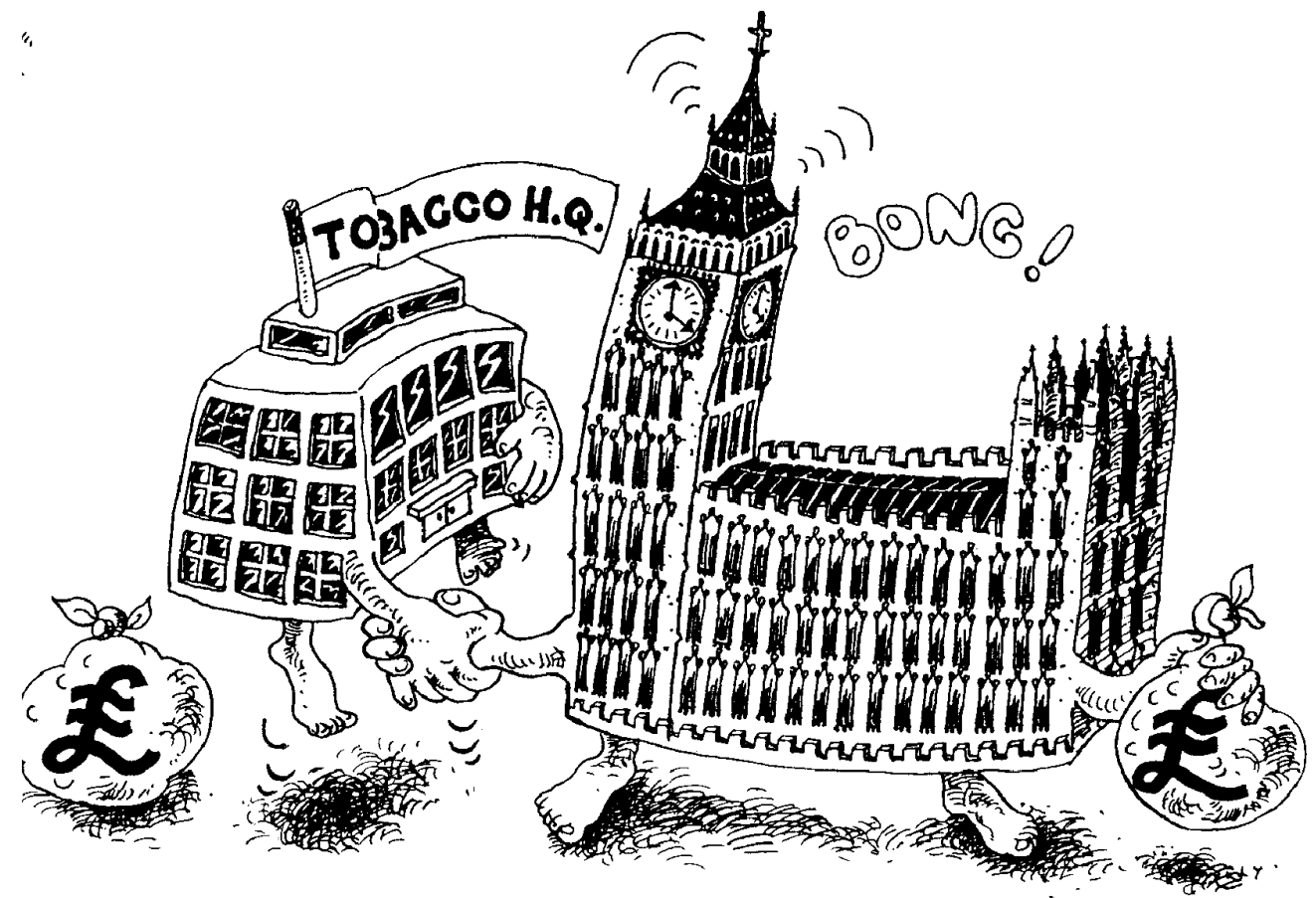

Thanks to Nicky Cornwall for use of the cartoon 